\title{
Extrativismo de bromélias no Estado do Paraná
}

\author{
Bromeliads wild harvesting in State of Paraná
}

Raquel Rejane Bonato Negrelle ${ }^{\mathrm{I}}$ Adilson Anacleto ${ }^{\mathrm{II}}$

\section{RESUMO}

Visando a contribuir para o melhor entendimento da participação da atividade extrativista no âmbito da comercialização de bromélias no Brasil, apresentou-se resultado de pesquisa que buscou: a) identificar e caracterizar os extrativistas de bromélias formalmente registrados e os informais no Estado do Paraná; b) identificar e caracterizar as metodologias de coleta, o preparo e vias de comercialização das plantas coletadas; c) levantar a opinião dos extrativistas sobre facilidades e dificuldades desta atividade. O extrativismo de bromélias no Paraná foi identificado em 12 municípios, englobando 31 famílias extratoras, predominantemente concentradas no litoral do Paraná $(n=10)$ e Município de Ortigueira ( $n=7)$. Foram identificados dois tipos básicos de extrativistas: residente e oportunista, com diferenças marcantes entre estes, especialmente no que se refere a volume e forma de extração. Foram identificadas 21 espécies submetidas ao extrativismo, sendo as mais frequentemente coletadas: Vriesea incurvata Gaudich. comercializada por 90\% dos entrevistados, Nidularium innocentii Lem. (77\%), Vriesea platynema Gaudich. (67\%), Tillandsia stricta Sol. ex Ker Gawl. (55\%) e Vriesea carinata Lem. (55\%).

Palavras-chave: produtos florestais não madeiráveis, plantas ornamentais, Bromeliaceae.

\section{ABSTRACT}

Aiming to contribute to the better understanding of the wild harvesting participation in the context of the bromeliads trade, the results from a study focused on: a) identifying and to characterizing the bromeliads wild harvesters (formally and not formally registered) in the State of the Paraná; b) identifying and characterizing the harvesting methodologies, preparation and trade routes, and c) surveying the harvesters opinion on the facilities and difficulties of bromeliads wild harvesting are presented. The bromeliads wild harvesting was detected in 12 municipalities at Parana State, involving 31 harvester families, most of them concentrated at the coastal zone (n=10) and Ortigueira Mun. (7). Two basic harvester types were identified: resident and opportunist with outstanding differences between them especially related to volume and forms of extraction. A total of 21 bromeliads species were identified as submitted to wild harvesting, being the more frequently collected: Vriesea incurvata Gaudich. (cited by $90 \%$ of the interviewed harvesters), Nidularium innocentii Lem. (77\%), Vriesea platynema Gaudich. (67\%), Tillandsia stricta Sol. ex Ker Gawl. (55\%) and Vriesea carinata Wawra (55\%).

Key words: Non timber forest products, Ornamental plants. Bromeliaceae.

\section{INTRODUÇÃO}

O termo extrativismo é utilizado para designar toda atividade de coleta de produtos naturais. De acordo com o IBGE (2009), o extrativismo vegetal no Brasil totalizou R \$4,6 bilhões, em 2008, dos quais $\mathrm{R} \$ 3,9$ bilhões foram provenientes da produção madeireira e $\mathrm{R} \$ 685,4$ milhões da produção não madeireira e, embora os dados descritos se configurem em importante fonte de informação, são predominantemente vinculados a sistemas “formais”

IDepartamento de Botânica, Laboratório de Ecologia, Setor de Ciências Biológicas, Universidade Estadual do Paraná (UFPR), CP 19031, 81531-970, Curitiba, PR, Brasil. E-mail:negrelle@ufpr.br. Autor para correspondência.

IIDepartamento de Administração, Faculdade Estadual de Filosofia, Ciências e Letras de Paranaguá (FAFIPAR), UFPR, Paranaguá, PR, Brasil. 
(legal ou comercial). Estes dados debilmente refletem a participação de sistemas ‘informais’ (ilegal, esporádico ou de subsistência) (WUNDER, 1999), os quais incluem o extrativismo para utilização de vários produtos como: coquilhos de açaí, amêndoas de babaçu, fibras de piaçava, erva-mate nativa, pó cerífero de carnaúba e castanha-do-pará. Há restrições legais para o extrativismo de espécies nativas, cujo licenciamento demanda a propriedade da terra e plano de manejo. Porém, muitos extrativistas não possuem posse de terra e há enormes lacunas de conhecimento ecológicobiológico e agronômico sobre as espécies alvo, além do que poucas autorizações são fornecidas. Contudo, isso não impede que a atividade seja exercida na clandestinidade (NEGRELLE et al., 2011).

Entre estas espécies submetidas a extrativismo ilegal, estão as plantas ornamentais, especialmente bromélias, as quais têm grande destaque em função de sua beleza, abundância e facilidade de obtenção em ambientes naturais, aliado ao seu alto valor comercial (NEGRELLE et al., 2011).

No Estado do Paraná, o extrativismo informal de bromélias tem sido reportado desde a década de 50 (MAFRA, 1952), impulsionado pelo interesse dos turistas que circulavam pelo litoral. A partir de 2000, embora as instituições de fiscalização, em função das pressões coletivas para a preservação dos remanescentes de Floresta Atlântica, iniciassem verdadeira cruzada contra o extrativismo das bromélias, estes esforços não foram suficientes para coibir a prática extrativista (ANACLETO \& NEGRELLE, 2009). Segundo NEGRELLE et al. (2011), há forte evidência de que, apenas em 2000, mais de 200.000 bromélias foram ilegalmente extraídas da Floresta Atlântica na região de Guaratuba, Paraná. O valor comercial deste montante seria em torno de US\$400.000,00. Em 2001, similarmente, cerca de 150.000 espécimes foram ilegalmente retiradas de unidades de conservação. No entanto, pouco se conhece dessa realidade extrativista no contexto atual.

Dessa forma, visando a contribuir para o melhor entendimento da participação da atividade extrativista no âmbito da comercialização de bromélias, apresenta-se resultado de pesquisa que buscou: a) identificar e caracterizar os extrativistas de bromélias no Estado do Paraná, bem como as metodologias de coleta, comercialização e as espécies mais extraídas; b) levantar a opinião dos extrativistas sobre a atividade, em termos de oportunidades, ameaças, fortalezas e debilidades; c) discutir sobre as implicações da realidade observada no contexto da sustentabilidade da atividade extrativista e conservação de bromélias.

\section{MATERIAL E MÉTODOS}

Para identificar a existência de extrativistas de bromélias formalmente registrados ou informais, foi protocolado um questionário junto a EMATER-PR, SEAB (Secretaria de Estado da Agricultura e Abastecimento do Paraná) e no IAP (Instituto Ambiental do Paraná). Paralelamente, consultou-se o cadastro SERFLOR/IAP e a relação dos associados da extinta Associação dos Produtores de Bromélias no Litoral. À medida que se conseguiu identificar alguns elementos da população objeto do estudo, esses indicaram outros, num processo denominado "snowball” ou amostragem autogerada (KOTLER, 2001).

A coleta de dados foi realizada a partir de entrevistas semi-estruturadas, ao total foram entrevistados 31 extratores, destes, a maioria eram classificados como residentes $(n=23)$ por possuir moradia próxima às regiões extratoras, sendo o restante classificados como oportunistas $(n=8)$ por residir em áreas urbanas.

Adicionalmente, foi organizado um diagnóstico rural participativo (DRP) entre 20 e 22 de novembro de 2008, de acordo com o proposto por VERDEJO (2006), com participação voluntária de apenas extratores residentes $(n=11)$. As fases da atividade foram orientadas, sem que os pesquisadores interferissem nas opiniões das pessoas que forneceram dados para a elaboração da matriz SWOT: Strengths (forças), Weakness (fraquezas), Opportunities (oportunidades) e Treathes (ameaças), relacionados à atividade extrativista (KOTLER, 2001). A matriz SWOT foi organizada conforme JIMENÉZ et al. (2007), agrupando os pontos fortes e fracos no contexto interno e as ameaças e oportunidades no contexto extra-propriedades. Como indicado em KOTLER (2001), cada opinião expressada na matriz SWOT foi avaliada quanto à respectiva influência exercida e sofrida, sendo então organizada uma matriz de impacto cruzado (ANACLETO, 2011).

\section{RESULTADOS}

De um total de 42 questionários encaminhados à EMATER-PR, SEAB e IAP, apenas sete informaram saber da existência do extrativismo. Entretanto, explicitaram não reconhecer a atividade como relevante, devido à existência de outras frentes agrícolas consideradas mais relevantes, como o cultivo de milho, soja, café e feijão.

O extrativismo de bromélias no Paraná foi identificado em 12 municípios, englobando 31 famílias extratoras, predominantemente concentradas no litoral 
do Paraná (n=10) e Município de Ortigueira (n=7). Deste total, 25 extrativistas se dispuseram a ser entrevistados e foram então identificados dois tipos básicos de extrativistas: residentes e oportunistas.

Os extratores residentes somaram, no total, 23 famílias, sendo aquelas que viviam próximas às áreas onde praticavam o extrativismo. A maior densidade dessas famílias foi registrada em Guaratuba (6), seguida de Ortigueira (5), Mauá da Serra (2), Reserva (2), Curitiba (1), Telêmaco Borba (1), Manoel Ribas (1), Matinhos (1), Paranaguá (1), São José dos Pinhais (1), Tijucas do Sul (1) e Morretes (1).

Inseriram-se neste grupo pequenos produtores de subsistência que se dedicavam ao cultivo de lavouras (banana, mandioca, arroz e hortaliças) e pequenos animais para consumo familiar, sendo os raros excedentes vendidos em bancas rústicas por estes construídos nas beiras das rodovias. Destes, treze eram proprietários da terra, cujo tamanho médio era de cerca de 3,0ha. Dez não possuíam a titularidade da terra, sendo considerados posseiros de áreas com tamanho médio de 0,7ha. Em ambos os casos, a maioria das propriedades apresentava restrições ambientais por estarem inseridas em áreas sob proteção ambiental.

A demanda externa determinava a periodicidade de coleta que era quinzenal para a maioria dos entrevistados $(n=14)$ ou, em menor escala, de forma mensal $(n=6)$ e semanalmente $(n=3)$. A coleta era direcionada apenas para plantas com inflorescência já emitida ou em pré-inflorescência.

O tempo médio de duração da coleta era de um a dois dias. Ao retornar, cada pessoa trazia consigo, dependendo do tamanho da planta coletada entre 12 e 15 unidades. Segundo os extrativistas residentes $(n=47 \%)$, estes coletavam apenas a metade do que estava à disposição, ficando o restante para dispersão de sementes e emissão de novos brotos. Cada família coletava aproximadamente 100 espécimes/mês. Após a coleta, estas eram acomodadas em estruturas rústicas no local da residência (estufas, telados cobertas de sombrite ${ }^{\circledR}$ ou bambu) para a venda.

A venda direta na propriedade do extrator foi registrada como meio mais comum de comercialização $(n=10)$, especialmente na Serra do Cadeado e no litoral. Os outros extratores $(n=13)$ disseram utilizar transporte coletivo (ônibus) para fazer a comercialização nos centros urbanos. Após a coleta, as bromélias eram limpas, retirando-se as folhas velhas e o seu excesso, o sistema radicular era limpo (raiz nua) e as plantas eram enroladas em jornais, formando tubos compactos que ocupavam menor espaço e posteriormente eram acondicionados em caixas de papelão para facilitar o transporte até o comprador.
Além da venda direta no varejo, alguns extrativistas residentes $(n=7)$ também explicitaram vender no atacado para varejistas de Curitiba, Londrina, Ponta Grossa e Telêmaco Borba no Paraná, assim como para Guaramirin, Garuva e Joinville, em Santa Catarina, sendo que os estabelecimentos comerciais do tipo "garden centers" $(n=8)$ foram os mais citados, seguido das floriculturas ( $n=5)$ e empresas de jardinagem (4).

$\mathrm{O}$ preço médio pago às plantas era cerca de $\mathrm{R}$ \$5,00 para as espécies de melhor aceitação no mercado (Vriesea incurvata Gaudich., Nidularium innocentii Lem., Vriesea platynema Gaudich., Tillandsia stricta Sol. ex Ker Gawl. e Vriesea carinata Wawra).

Assim, a atividade de extrativismo e comercialização de bromélias, no ano de 2008, conferia às famílias de extrativistas residentes aproximadamente $\mathrm{R} \$ 500 /$ mês. Na maioria dos casos, o extrativismo era a única fonte de renda familiar.

Apenas três dos entrevistados, dois no município de Ortigueira e um em Guaratuba comprovaram formalmente possuir autorização para a coleta de plantas. Quando questionados sobre os motivos pelos quais permanecem na clandestinidade do extrativismo, alguns entrevistados $(n=5)$ explicitaram que desconheciam a necessidade de autorização de extração, não reconhecendo a atividade como ilegal ou criminosa. Outros extrativistas $(n=5)$ informaram que já haviam tentado obter a autorização formal para extração, porém a falta de título de propriedade da terra e o tamanho reduzido de suas propriedades foram os impeditivos na regularização da situação. O desconhecimento de quais seriam os procedimentos para regularizar a condição de extrator também foi citado nas entrevistas $(n=6)$.

Apenas dois extrativistas indicaram possuir cultivos em andamento para futura substituição ao extrativismo. Significativa parcela $(n=10)$ mostrou não ter intenção imediata de cultivar bromélias, devido à inexistência de recursos para construção de viveiros $(n=6)$, tempo de demora para produzir $(n=2)$ e a elevada disponibilidade na floresta $(n=2)$.

O segundo tipo de extratores eram os classificados como oportunistas, que residiam fora das áreas onde praticavam o extrativismo, sendo que estes frequentemente atuavam sob encomenda dos comerciantes, proprietários de grandes floriculturas e “garden centers”, localizados nos municípios de Joinville e Guaramirin em Santa Catarina e Curitiba no Paraná.

Registrou-se a existência desta classe de extrativistas em Guaratuba ( $n=4)$, Tijucas do Sul $(n=3)$ e Antonina $(n=1)$. No entanto, apenas dois extrativistas 
de Guaratuba concordaram em responder à pesquisa. De acordo com os entrevistados, a coleta ocorria nos finais de semana, preferencialmente em período de chuvas, quando a fiscalização era reduzida. A coleta ultrapassava mil unidades mês por extrator e englobava plantas em vários estágios de crescimento e não somente na fase de emissão de inflorescência ou préinflorescência, sendo que, devido a este motivo, o preço médio pago a estes extrativistas era de $\mathrm{R} \$ 1,50$ por planta, menor que o praticado na outra categoria.

Os extrativistas oportunistas eram responsáveis pelo transporte das bromélias coletadas até os centros de comercialização. Por estarem mais sujeitos à casualidade da fiscalização, estes mostraram estar bastante cientes da situação de ilegalidade e riscos associados à sua atividade. Porém, ainda assim não mostraram intenção de legalizarem sua situação. Entre os motivos citados, registraram-se a falta de vinculo com a zona rural, não ter propriedade de terra, a inexistência de recursos financeiros e também o desejo de abandonar a atividade em função do receio de ocorrer o embate com as instituições de fiscalização ambiental que resultasse em prisões.

Ao todo, foram identificadas 21 espécies coletadas pelos dois tipos de extratores paranaenses, sendo as espécies mais frequentemente coletadas a Vriesea incurvata Gaudich., comercializada por $90 \%$ dos entrevistados, Nidularium innocentii Lem. (77\%), Vriesea platynema Gaudich. (67\%), Tillandsia stricta Sol. ex Ker Gawl. (55\%) e Vriesea carinata Wawra (55\%).

Os extrativistas que participaram do DRP fizeram inferências à possibilidade de criação de um selo verde como a principal oportunidade vinculada ao extrativismo de bromélias. Essa ação permitiria incrementar as vendas e consequentemente a renda familiar, resultando em melhoria da qualidade de vida destas famílias (Tabela 1).

Dentre os fatores que poderiam ameaçar a continuidade do extrativismo, registrou-se maior ênfase à falta de organização coletiva, na visão dos extrativistas, o que enfraquecia a capacidade local de solucionar problemas comuns, sendo considerada uma ameaça a todos e a cada um. A inacessibilidade ao crédito para custeio da atividade e a quase inexistência de técnicos agrícolas qualificados para atender o extrativismo também foram citados como ameaças importantes no contexto extrativista (Tabela 1).

A dependência financeira do extrativismo e a dificuldade de implantar o cultivo, devido ao longo tempo que este demanda, assim como falta de conhecimento técnico, foram referenciadas como principais debilidades enfrentadas pelos extrativistas (Tabela 1).

A viabilidade da substituição do extrativismo por cultivo, a renda adicional obtida com o extrativismo e a possibilidade de comercializar seu produto na sua propriedade foram expressas como as principais fortalezas associadas à atividade extrativista (Tabela 1).

\section{DISCUSSÃO}

Apesar de desconhecido ou não valorizado pelos órgãos competentes, o extrativismo ilegal de bromélias realizado no Paraná abastece uma parte significativa do comércio formal de bromélias tanto em estabelecimentos paranaenses como de outros estados vizinhos.

Tabela 1 - Analise SWOT na percepção do extrator de bromélias.

\begin{tabular}{|c|c|c|c|}
\hline Oportunidades & IR & Ameaças & IR \\
\hline Concepção de um selo "verde" & 20,8 & Falta de organização comunitária & 13,4 \\
\hline Melhoria da qualidade de vida das famílias envolvidas & 9,71 & $\begin{array}{l}\text { Crédito de Investimento/custeio de safra inacessível aos } \\
\text { extratores }\end{array}$ & 12,2 \\
\hline Incrementar a renda familiar & 9,71 & Possibilidade de extinção de espécies & 12,0 \\
\hline $\begin{array}{l}\text { Proximidade de grandes centros consumidores favorecendo } \\
\text { o comércio }\end{array}$ & 8,63 & Número limitado de técnicos especialistas no assunto & 10,3 \\
\hline Endemismo de espécies com potencial comercial & 8,09 & Burocracia para legalização da extração & 9,3 \\
\hline Fortalezas & IR & Debilidades & IR \\
\hline Viabilidade da substituição da extração por produção & 23,0 & Dependência financeira do extrativismo & 18,5 \\
\hline Renda obtida com o extrativismo & 19,7 & Longo tempo de cultivo & 11,3 \\
\hline Venda é praticada na propriedade & 16,4 & Desconhecimento sobre implantação de cultivos & 7,4 \\
\hline Mão de obra disponível nas propriedades & 8,7 & $\begin{array}{l}\text { Inexistência de plano de manejo para legalizar } \\
\text { extrativismo }\end{array}$ & 7,2 \\
\hline Elevado número de espécies comerciais nas propriedades & 8,2 & Baixa qualidade da produção derivada do extrativismo & 7,2 \\
\hline
\end{tabular}

IR: Índice de relevância.

Ciência Rural, v.42, n.6, jun, 2012. 
O extrativismo de bromélias não é necessariamente proibido pelas leis ambientais brasileiras (ANACLETO, 2011). Entretanto, a formalização do extrativismo é um processo sujeito a requerimentos bem específicos e dependente da regulamentação em nível estadual, que ainda não foi efetivada no Paraná. Dessa forma, a formalização é pouco factível nas atuais circunstâncias.

A facilidade do acesso a ambientes em que naturalmente crescem bromélias, a alta densidade deste recurso nestes locais associados à falta de recursos financeiros, problemas fundiários, a falta de apoio técnico-agrícola e limitações ambientais são fatores que desestimulam a implantação de sistemas de cultivo e reforçam o padrão extrativista.

Os órgãos ambientais não reconhecem integralmente os problemas associados ao extrativismo ilegal, apenas ressaltam as dificuldades da identificação, mensuração e adequado monitoramento da atividade ilegal, sem uma adequada contextualização econômica do montante extraído e comercializado. Neste cenário de invisibilidade, com a crescente demanda do comércio de plantas ornamentais, várias espécies de bromélias estão ameaçadas de extinção devido à superexploração sem controle (ROE, 2002; IBAMA, 2007).

Os dois tipos de extratores (residente e oportunista), embora apresentem diferenças marcantes, possuem perspectiva socioeconômica similar. O extrativismo praticado pelos extratores residentes pôde ser categorizado como "estratégia diversificada", ou seja, o extrativismo estava integrado a outras atividades praticadas nas áreas onde residiam e seu entorno, que, em sua pluralidade, configuravam a subsistência/ rendimento familiar.

Por outro lado, os extratores oportunistas enquadravam-se na “estratégia de adaptação". Nesse caso, o extrativismo era a única fonte de renda familiar, mas o rendimento advinha de vários produtos extraídos da natureza, que, em geral, não extrapolava um salário mínimo. A opção extrativista resultava da precária capacitação pessoal e falta ou limitada oferta de outras oportunidades de emprego.

Em ambos os casos, estes extrativistas podem ser categorizados como "empreendedores viradores” (SOUZA NETO, 2003), ou seja, conforme descrito por SILVA \& PEREIRA (2007), este tipo de empreendedores, ao invés de optar pelo empreendimento próprio por vocação ou por ter descoberto uma oportunidade no mercado, o fazem por necessidade, impelidos pela situação em que se encontram, quase sempre desempregados, como no caso dos extratores oportunistas, ou frequentemente impedidos de desempenhar sua função original, como no caso dos extratores residentes, frente às restrições ambientais em relação à agricultura por estarem inseridos em áreas de unidades de conservação ambiental, tornando ainda mais precárias as condições de possibilidade de reprodução social e econômica destes extratores (DUMORA, 2006; FERREIRA, 2010).

O empreendedorismo, nessa perspectiva, faz com que os extrativistas participem de um círculo vicioso e perverso: extraem porque são pobres e sem alternativas e, por serem pobres e sem alternativas, extraem(BELCHER, 2005).

De modo geral, os extrativistas visualizaram, de maneira tímida, as potencialidades associadas ao extrativismo, indicando desconhecer o mercado em que se inserem e suas respectivas potencialidades (Tabela 1). O mercado de floricultura e comércio de plantas ornamentais cresceu de forma expressiva nos últimos anos, com perspectiva de continuidade deste crescimento positivo no Brasil (IBRAFLOR, 2011). Especificamente no Estado do Paraná, nos últimos 10 anos, avançou 230\%, sendo que o valor bruto da produção da atividade do Estado, em 2007, foi de R\$ 47, 383 milhões (EHLERT, 2008).

Estes extrativistas reconheceram, de maneira dispersa, diferentes níveis de ameaças, colocando sua própria inabilidade de organizar-se comunitariamente como a maior ameaça para a melhoria do desempenho de sua atividade (Tabela 1). Identificaram seu baixo poder econômico e falta de conhecimento técnico adequado como suas principais debilidades no que se refere à sustentabilidade da atividade extrativista e implantação de sistemas de cultivo. No entanto, foram explícitos em apontar de forma bastante coerente que o cultivo seria uma saída potencial para incrementar seu rendimento e melhorar sua condição de vida, salientando que este cultivo não demandaria grandes áreas e poderia utilizar a mão de obra familiar (Tabela 1).

No entanto, como evidenciado por DUMORA (2006) para comunidades da zona costeira paranaense, os extratores não possuem uma grande margem de manobra para mudar o quadro precário das condições de vida em que se encontram. Aqueles que estão envolvidos de maneira quase que exclusiva nas atividades ilícitas, buscam outras atividades geradoras de renda ou pensam em ir embora da comunidade para os centros urbanos, onde poderão optar por outros empregos.

Contrapondo a situação evidenciada, em outras regiões, o extrativismo de produtos florestais não madeiráveis (PFNM), como as bromélias, tem sido apontado como forma de melhoria de renda para populações próximas a ambientes florestados, promovendo simultaneamente o desenvolvimento econômico e a conservação da floresta (NEPSTAD \& SCHWARTZMAN, 1992), além disso, tal atividade contribui para manutenção das famílias no meio rural. 
De acordo com FERREIRA (2010), as comunidades extrativistas enfrentam múltiplas e severas limitações, é importante ponderar que são pobres porque tem precário acesso ao mercado, insuficiente capital humano, insuficiente capital produtivo, instituições fracas e, geralmente, poder de barganha fraco (HOMMA, 1993; BELCHER, 2005).

A demanda por espécies novas diferentes é uma constante no comércio de plantas ornamentais, tanto em nível nacional como internacional. O Brasil, devido à sua alta biodiversidade, tem uma oportunidade enorme de usar recursos nativos para melhorar a qualidade de vida de comunidades rurais com baixo ingresso. A floricultura é uma atividade que demanda pequenas áreas e pode empregar força de trabalho feminina, assim promovendo equidade de gênero e atuando na redução da velocidade do êxodo em áreas rurais.

Adicionalmente, para permitir a viabilidade econômica da atividade extrativista, sem prejudicar as demandas crescentes de mercado e causar impacto negativo ao ambiente e as espécies fonte, há necessidade de manejar adequadamente estas espécies em ambiente natural assim como promover a domesticação e o estabelecimento de unidades de cultivo, conforme sugerido por HOMMA (1993).

\section{CONCLUSÃO}

Foram identificados dois tipos básicos de extrativistas, o residente e o oportunista. De acordo com estes, a criação de um selo verde seria a principal oportunidade e a viabilidade da substituição da extração por produção, a principal fortaleza. Como principais entraves, destacaram-se a falta de organização coletiva e a dificuldade de implantar cultivos.

\section{REFERÊNCIAS}

ANACleto, A. Bromélias no Paraná: cultivo, extrativismo e comercialização. 2009. 173f. Tese (Doutorado em Agronomia - Produção Vegetal) - Universidade Federal do Paraná, Curitiba, PR.

ANACLETO, A.; NEGRELLE, R.R.B. Extrativismo de rametes e propagação vegetativa de Aechmea nudicaulis (L.) Griseb. Bromeliaceae. Scientia Agraria, Curitiba, v.10, n.1, p.8588, 2009. Disponível em: <http://ojs.c3sl.ufpr.br/ojs2/index.php /agraria/article/view/13529>. Acesso em: nov. 2010.

BELCHER, B.M. Forest product markets, forest and poverty reduction. International Forestry Review, Shropshire (UK), v.7, n.2, p.82-89, 2005.

DUMORA, C. Viver e sobreviver numa Área de Proteção Ambiental: o caso da pequena agricultura familiar em uma das comunidades rurais da APA de Guaraqueçaba. Desenvolvimento e Meio Ambiente, Curitiba, n.14, p.47-67, 2006.
EHLERT, A. Produção de flores cresce e deixa preços menores. Portal Bem Paraná 23 set 2008. Disponível em: <http://www.bemparana.com.br/index.php?n=82512\&t=producaode-flores-cresce-e-deixa-precos-menores>. Acesso: abr. 2011.

FERREIRA, M. Comunidades rurais de GuaratubaParaná: os limites e as possibilidades da opção extrativista. 2010. 221f. Tese (Doutorado em Agronomia - Produção Vegetal) - Universidade Federal do Paraná, Curitiba, RS.

IBAMA (Instituto Brasileiro de Meio Ambiente). Exportação necessita anuência previa do IBAMA. Brasília, 2007. 46p.

IBGE (Instituto Brasileiro de Geografia e Estatística). Produção da extração vegetal e da silvicultura 2009. Comunicação Social 24 de novembro de 2010. Disponível em: <http:// www.ibge.gov.br/home/presidencia/noticias/ noticia_impressao.php?id_noticia=1760>. Acesso: mar. 2011.

IBRAFLOR (Instituto Brasileiro de Floricultura). Floricultura: perfil do setor. Disponível em: http://<www.aprendendoaexportar.gov.br/ flores/setor/perfil.asp.>. Acesso: mar. 2011.

HOMMA, A.K.O. Extrativismo vegetal na Amazônia: limites e oportunidades. Brasília: EMBRAPA-SPI, 1993. 202p.

JIMENÉZ, M.E.M. et al. Bases para el manejo comunitario de bromélias ornamentales. Oaxaca, México: Gaia/Raises, 2007. 112p.

KOTLER, P. Administração de marketing: análise, planejamento, implementação e controle. São Paulo: Atlas, 2001. 730p.

MAFRA, J.S. História de Guaratuba. Guaratuba: Prefeitura Municipal, 1952. 147p.

NEGRELLE, R.R.B. et al. Bromeliad ornamental species: conservation issues and challenges related to commercialization. Acta Scientiarum. Biological Sciences, Maringá, v.34, n.1, p.91-100, 2011. Disponível em: <http://eduem.uem.br/ojs/ index.php/ActaSciBiolSci/article/view/7314/pdf $>$. Acesso em: nov. 2011. doi:10.4025/actascibiolsci.v34il.7314.

NEPSTAD, D.C.; SCHWARTZMAN, S. Non timber forest products from tropical forests. Evaluation of a conservation and development strategy. Economic Botany, New York, v.9, p.1-176, 1992.

ROE, D. Making a killing or making a living: wildlife trade, trade controls, and rural livelihoods. Biodiversity and Livelihoods Issues, London (UK), n.6, p.1-109, 2002.

SILVA, M.S.; PEREIRA, J.C.O. “Virador": estilo de sobrevivência do empreendedor brasileiro. Revista Científica da FAI, Santa Rita do Sapucaí (MG), v.7, n.1, p.62-71, 2007.

SOUZA NETO, B. Contribuição e elementos para um metamodelo empreendedor brasileiro: o empreendedor de necessidade do "virador". Rio de Janeiro: COPPE/UFRJ, 2003. 314p.

VERDEJO, M.E. Diagnóstico rural participativo, um guia prático. Brasília: SAF/ MDA, 2006. 62p.

WUNDER, S. Value determinants of plant extractivism in Brazil: an analysis of the data from the IBGE agricultural census. Rio de Janeiro: IPEA, 1999. 59p. 